\title{
Optimizing glycemic control: clinical utility of exenatide prolonged release injection
}

This article was published in the following Dove Press journal:

Research and Reports in Endocrine Disorders

25 September 2012

Number of times this article has been viewed

\section{Giuseppe Derosa}

Pamela Maffioli

Department of Internal Medicine and Therapeutics, University of Pavia, Fondazione IRCCS Policlinico

S Matteo, Pavia, Italy
Correspondence: Giuseppe Derosa Department of Internal Medicine and Therapeutics, University of Pavia, Fondazione IRCCS Policlinico S Matteo, Pavia, Italy, Ple C Golgi, 2-27I00 PAVIA, Italy

Tel +3903825262 17

Fax +390382526259

Email giuseppe.derosa@unipv.it
Abstract: Despite the large variety of antidiabetic drugs currently available, reaching an adequate glycemic control is still difficult. Recently, a new exenatide long acting release (LAR) formulation, which can be administered once a week, has been released. We conducted a review analyzing the clinical utility of this new formulation and its place in antidiabetic therapy, and included the most important studies about exenatide LAR in the latest 10 years. A systematic search strategy was developed to identify randomized controlled trials in both MEDLINE and the Cochrane Register of Controlled Trials. The terms "exenatide," "exenatide long active release," "GLP-1 agonists," "incretins," and "glycemic control" were incorporated into an electronic search strategy that included the Dickersin filter for randomized controlled trials. We concluded that exenatide LAR can be a valid option for the treatment of type 2 diabetes mellitus because it showed to be effective in reducing $\mathrm{HbA}_{1 \mathrm{c}}$, and because of its pleiotropic effects, such as the reduction of blood pressure, the improvement of the patient's lipid profile, and the positive effects on body weight and $\beta$-cell function. Moreover, exenatide LAR has demonstrated a favorable cost/effectiveness ratio, and its once weekly administration may help to increase patient compliance.

Keywords: $\beta$-cell, body weight, exenatide long acting release, glycemic control

\section{Introduction}

Type 2 diabetes mellitus is a chronic disease characterized by three major metabolic abnormalities: impaired insulin action, insulin secretory dysfunction, and increased endogenous glucose output. ${ }^{1-3}$ In most individuals with type 2 diabetes mellitus, hyperglycemia results from a failure of insulin secretion from the $\beta$-cells to adequately compensate for insulin resistance in peripheral tissues. ${ }^{4}$ The importance of an early, intensified approach to metabolic control has been clearly demonstrated by the long-term results of the United Kingdom Prospective Diabetes Study, showing that the benefits of tight blood glucose control extended well beyond the end of the study and persisted after a period of over 10 years. ${ }^{5}$ This was also confirmed by the Diabetes Control and Complications Trial/Epidemiology of Diabetes Interventions and Complications study that showed that decreasing glycated hemoglobin $\left(\mathrm{HbA}_{1 \mathrm{c}}\right)$ can slow the progression of established microalbuminuria to macroalbuminuria, as well as the impaired glomerular filtration rate. ${ }^{6}$

According to the latest American Diabetes Association guidelines, ${ }^{7}$ lowering $\mathrm{HbA}_{1 \mathrm{c}}$ to below or around $7 \%$ has been shown to reduce microvascular and neuropathic complications of diabetes and, if implemented soon after the diagnosis of diabetes, is associated with a long-term reduction in macrovascular disease. Therefore, a reasonable $\mathrm{HbA}_{1 \mathrm{c}}$ goal for many non-pregnant adults is $<7 \%$. submit your manuscript | www.dovepress.com

Dovepress

http://dx.doi.org/10.21 47/RRED.S24237
Research and Reports in Endocrine Disorders 2012:2 4I-5I

(C) 2012 Derosa and Maffioli, publisher and licensee Dove Medical Press Ltd. This is an Open Access article which permits unrestricted noncommercial use, provided the original work is properly cited. 
Lifestyle modification can improve glycemic control as well as body weight, blood pressure, insulin-resistance, and lipid profiles; however, behavioral modifications are inherently difficult and most patients eventually require multiple medications to achieve their desired goals. ${ }^{7}$

\section{Current therapeutic strategies}

Many antidiabetic agents are available, and decisions regarding which to prescribe should be done after examining the characteristic of each of the various drugs (Table 1).

Biguanides (metformin) act by decreasing hepatic glucose output and lowering fasting glycemia. Typically, metformin monotherapy lowers $\mathrm{HbA}_{1 \mathrm{c}}$ levels by $1.5 \% .{ }^{89}$ They are generally well tolerated, with the most common adverse effects being experienced in the gastrointestinal tract.

Sulfonylureas (glipizide, glibenclamide, glimepiride, gliclazide) lower glycemia by enhancing insulin secretion. In terms of efficacy, they appear to be similar to metformin, lowering $\mathrm{HbA}_{1 \mathrm{c}}$ levels by $1.5 \%{ }^{10,11}$ The major adverse side effect is hypoglycemia, which can be prolonged and life threatening, but such episodes - characterized by a need for assistance, as well as coma, or seizure - are infrequent.

Like the sulfonylureas, glinides (repaglinide and nateglinide) enhance insulin secretion although they bind to a different site within the sulfonylurea receptor. ${ }^{11}$ They have a shorter circulating half-life than the sulfonylureas and must be administered more frequently. Of the two glinides currently available in the US, repaglinide is almost as effective as metformin or the sulfonylureas, as they decrease $\mathrm{HbA}_{1 \mathrm{c}}$ levels by $1.5 \%$, as with sulfonylureas, the most reported adverse side effect is hypoglycemia.

The $\alpha$-glucosidase inhibitors (acarbose and miglitol) reduce post-prandial hyperglycemia by delaying the breakdown of carbohydrates in the gut, and consequently slowing down the absorption of sugars. They are less effective in lowering glycemia than metformin or the sulfonylureas, and reduce $\mathrm{HbA}_{1 \mathrm{c}}$ levels by $0.5 \%-0.8 \%{ }^{12}$ however, these agents significantly decrease the post-prandial rise in glucose without increasing circulating insulin levels and without causing hypoglycemia. ${ }^{13}$ Since carbohydrates are absorbed more distally, malabsorption and weight loss do not occur; however, increased delivery of carbohydrates to the colon commonly results in increased gas production and gastrointestinal symptoms.

Thiazolidinediones (pioglitazone) are peroxisome proliferator-activated receptor-modulators; they increase the sensitivity of muscle, fat, and liver to endogenous and exogenous insulin ("insulin sensitizers"). ${ }^{14}$ The data regarding the effectiveness of thiazolidinediones in lowering blood glucose when used as monotherapy have demonstrated a $0.5 \%-1.4 \%$ decrease in $\mathrm{HbA}_{10}{ }^{15}$ The thiazolidinediones appear to have a more durable effect on glycemic control, particularly when compared with sulfonylureas. ${ }^{15}$ The most common adverse effects associated with thiazolidinediones are weight gain and fluid retention, with peripheral edema and a two-fold increased risk for congestive heart failure; ${ }^{16}$ however, the weight gain can be reduced by a combination of thiazolidinediones and metformin. ${ }^{17}$ Pioglitazone should be not used in post-menopausal women with a history of osteoporosis because of the increased risk of fractures in the distal upper limbs (forearm, hand, and wrist) or distal lower limbs (foot, ankle, fibula, and tibia), as previously reported. ${ }^{18}$

In an attempt to address treatment concerns of many traditional medications for type 2 diabetes, in the last 10 years incretin-based therapies have been developed in clinical practice. Incretins are hormones that work to increase insulin secretion; there are two main incretin hormones in humans: the glucose-dependent insulinotropic peptide and the glucagon-like peptide-1 (GLP-1). GLP-1 is secreted by intestinal L-cells, mainly in response to food intake and acts to stimulate glucose-dependent insulin secretion, suppress glucagon secretion, and moderate appetite by delaying

Table I Characteristics of various antidiabetic drugs

\begin{tabular}{|c|c|c|c|}
\hline Class & Main agents of the class & Mechanism of action & Main adverse events \\
\hline Biguanides & Metformin & They decrease hepatic glucose output & Gastrointestinal events \\
\hline Sulfonylureas & Glipizide, glibenclamide, glimepiride, gliclazide & They enhance insulin secretion & Hypoglycemia \\
\hline Glinides & Repaglinide and nateglinide & They enhance insulin secretion & Hypoglycemia \\
\hline$\alpha$-glucosidase inhibitors & Acarbose and miglitol & $\begin{array}{l}\text { They inhibit } \alpha \text {-glucosidase, delaying the } \\
\text { breakdown of carbohydrates in the gut }\end{array}$ & $\begin{array}{l}\text { Meteorism and } \\
\text { gastrointestinal events }\end{array}$ \\
\hline Thiazolidinediones & Pioglitazone & $\begin{array}{l}\text { They act as peroxisome proliferator- } \\
\text { activated receptor-modulators }\end{array}$ & $\begin{array}{l}\text { Weight gain and fluid } \\
\text { retention }\end{array}$ \\
\hline GLP-I agonists & Exenatide and liraglutide & They bind to the GLP-I receptor & Nausea, vomiting, or diarrhea \\
\hline DPP-4 inhibitors & Sitagliptin, vildagliptin, saxagliptin, linagliptin & They inhibit the enzyme DPP-4 & Upper respiratory infections \\
\hline
\end{tabular}

Abbreviations: GLP-I, glucagon-like peptide-I; DPP-4, dypeptidil peptidase-4. 
gastric emptying and reducing hunger. ${ }^{19}$ It also promotes $\beta$-cell proliferation and probably neogenesis, while reducing apoptosis in animal models. ${ }^{20-22}$ Dipeptidyl peptidase-4 (DPP-4) inhibitors (sitagliptin, vildagliptin, saxagliptin, linagliptin) are small molecules that enhance the effects of GLP-1 and glucose-dependent insulinotropic peptide, increasing glucose-mediated insulin secretion and suppressing glucagon secretion. ${ }^{23-26}$ In clinical trials performed to date, DPP- 4 inhibitors lower $\mathrm{HbA}_{1 \mathrm{c}}$ levels by $0.6 \%-0.9 \%$, are weight neutral, and are relatively well tolerated. They do not cause hypoglycemia when used as monotherapy. The potential for this class of compounds to interfere with immune function is of concern, as an increase in upper respiratory infections has been reported. ${ }^{27,28}$

GLP-1 agonists such as exenatide (injected twice daily) and liraglutide (injected once daily) act as an incretin mimetic; they have the structural similarity of, and bind to, the receptor for GLP-1, and they display a broad range of activities relevant to improving glycemic control. They have a much longer half-life after injection than native GLP-1 due to the absence of alanine at position two, which is recognized by DPP-4; this characteristic makes them resistant to DPP-4 cleavage. They appear to lower $\mathrm{HbA}_{1 \mathrm{c}}$ levels by $0.5 \%-1.0 \%$, mainly by lowering post-prandial blood glucose levels. ${ }^{29-32}$ Exenatide also suppresses glucagon secretion and slows gastric motility. It is not associated with hypoglycemia, but causes a relatively high frequency of gastrointestinal disturbances, with $30 \%-45 \%$ of treated patients experiencing one or more episodes of nausea, vomiting, or diarrhea. ${ }^{29}$

Recently a new formulation of exenatide, the exenatide long acting release (LAR) to be administered once a week, has been released. We conducted a review analyzing the clinical efficacy and safety of this new formulation, evaluating if exenatide LAR can be a valid option for improving glycemic control in patients with uncontrolled type 2 diabetes.

\section{Material and methods}

A systematic search strategy was developed to identify randomized controlled trials in both MEDLINE (National Library of Medicine, Bethesda, MD; 2001 through June 2012) and the Cochrane Register of Controlled Trials (The Cochrane Collaboration, Oxford, United Kingdom). The terms "exenatide," "exenatide long active release," "GLP-1 agonists," "incretins," and "glycemic control" were incorporated into an electronic search strategy that included the Dickersin filter for randomized controlled trials. ${ }^{33}$ The bibliographies of all identified randomized trials and review articles were examined to look for additional studies of interest. We reviewed all of the citations retrieved from the electronic search to identify potentially relevant articles for this review. We subsequently reviewed the potential trials to determine their eligibility.

To qualify for inclusion, clinical trials were required to meet a series of predetermined criteria regarding study design, study population, interventions evaluated, and outcomes measured. Studies were required to be randomized trials comparing exenatide LAR at any dosage with any other antidiabetic drug in type 2 diabetic patients. Eligible trials had to present results on glycemic control or adverse events. Two different outcomes related to glycemic control decrease were of primary interest: (1) the proportion of individuals within each treatment group achieving clinically significant $\mathrm{HbA}_{1 \mathrm{c}}$ reduction; and (2) the mean amount decrease (in $\mathrm{mg} / \mathrm{dL}$ or $\mathrm{mmol} / \mathrm{L}$ ) of post-prandial glycemia (PPG) within each treatment group. Variations of fasting plasma glucose (FPG), HOMA index, systolic (SBP) and diastolic blood pressure (DBP), lipid profile, insulin resistance, and inflammatory parameters, which occurred during various trials, were secondary outcomes of interest, as was the frequency of patients having one or more adverse events.

The following data were abstracted into standardized case report forms: authors; year of publication; country of study; source of funding; study goal; means of randomization and blinding; duration of treatment; treatment characteristics; sex of patients; quantity of and reasons for study withdrawal; $\mathrm{HbA}_{1 \mathrm{c}}$ and age characteristics of the treatment and control groups; outcomes; and adverse event data. A validated, three-item scale was used to evaluate the overall reporting quality of the trials selected for inclusion in the present review. This scale provided scoring for randomization $(0-2$ points), double-blinding (0-2 points), and accounting for withdrawals (1 point). Scores ranged between 0 and 5, and scores of 3 indicated a study of high quality; ${ }^{34}$ study selection was restricted to randomized controlled trials to ensure the inclusion of only high quality evidence.

\section{Exenatide LAR mechanism of action and route of elimination}

Endogenous GLP-1 has a very short half-life (1-5 minutes) because of rapid degradation by DPP-4, which restricts its therapeutic usefulness. ${ }^{35}$ The first formulation of exenatide released, to be administered twice a day (BID), is a synthetic exendin-4, first identified and isolated in high concentrations from the salivary secretions of the Gila monster (Heloderma suspectum) within minutes of ingesting a meal..$^{36,37}$ Exendin- 4 shares $53 \%$ of its amino acid sequence identity 
with human GLP-1 and binds directly to GLP-1 receptors. ${ }^{38}$ Exenatide is eliminated by the kidneys exclusively, by way of glomerular filtration and subsequent tubular catabolism. ${ }^{39-41}$ In patients with renal dysfunction, exenatide shows reduced clearance and may thereby increase the risk of exposuredependent side effects. ${ }^{42}$

The exenatide LAR formulation was later developed, using biodegradable polymeric microspheres that entrap exenatide. ${ }^{43,44}$ Exenatide is incorporated into a matrix of poly(D,L-lactide-co-glycolide), which previously has been used as a biomaterial in sutures and in extended release preparations that allow for gradual drug delivery at controlled rates. ${ }^{45}$ Like exenatide BID, exenatide LAR is also eliminated by the kidneys.

\section{Clinical utility of exenatide prolonged release injection}

Exenatide LAR can be used together with other antidiabetic drugs in adult patients whose blood glucose levels are not adequately controlled with the maximum tolerated doses of the other medications. It can be used with metformin, sulfonylurea, or pioglitazone in monotherapy, or with a metformin and sulfonylurea, or metformin and pioglitazone combination at the recommended dosage of $2 \mathrm{mg}$ to be administered as one injection under the skin once a week on the same day each week in the abdomen, thigh, or back of the upper arm. ${ }^{46}$ Patients inject themselves using a kit supplied with the medicine. When exenatide is added to a sulfonylurea, a reduction of sulfonylurea dose may be needed in order to reduce the risk of hypoglycemia (Table 1).

\section{Adverse events}

The most common side effects reported with exenatide LAR were mainly problems affecting the stomach and gut, including vomiting, diarrhea, and constipation. Nausea was the most common single side effect, which was mainly seen at the start of treatment and decreased over time. In addition, reactions at the site of injection, low blood sugar levels - especially when used in combination with a sulfonylurea - and headache occurred. Most side effects were mild to moderate in intensity. As was the case for liraglutide, exenatide postmarketing reports also indicated that there was an increased risk of pancreatitis, including fatal and non-fatal hemorrhagic or necrotizing pancreatitis; in this case, the treatment should be discontinued and not restarted. ${ }^{29}$

Exenatide LAR should not be used in patients with severe renal impairment or end-stage renal disease, and it should be used with caution in patients with renal transplantation.
Its use is not recommended in patients with severe gastrointestinal disease (eg, gastroparesis). Post-marketing reports highlighted an increased international normalized ratio with concomitant use of warfarin, which sometimes occurred with bleeding. ${ }^{46}$

Recently, the Food and Drug Administration (FDA) conducted a study evaluating the future potential of cardiovascular adverse events as a result of the effects of exenatide LAR on heart rate. ${ }^{47}$ Fridericia's corrected QT intervals were analyzed in the Phase 3 DURATION-1 study at baseline and at 14 and 30 weeks in 148 diabetic patients treated with exenatide LAR $2 \mathrm{mg}$ once weekly. ${ }^{48}$ In this analysis, exenatide once weekly was associated with a small (but significant) increase in Fridericia's corrected QT interval of $1.7 \mathrm{msec}$ and $3 \mathrm{msec}$ at 14 and 30 weeks, respectively. However, after a study aimed at evaluating this aspect was conducted, no significant effect on the QT interval were observed. ${ }^{47}$ Moreover, in June 2011, the FDA issued a warning about liraglutide, as it seemed to cause dose-dependent and treatment-duration-dependent thyroid C-cell tumors at clinically relevant exposures in both genders of rats and mice; ${ }^{49}$ exenatide LAR showed a minor risk for the development of thyroid cancer compared to liraglutide, but to better quantify the risk, the FDA has required the manufacturer of exenatide LAR to conduct additional rodent studies to better identify this thyroid issue. ${ }^{50}$

When exenatide LAR is used in combination with a sulfonylurea, the risk for hypoglycemia was increased. In this case, clinicians should consider reducing the dose of the sulfonylurea. Regarding hepatic toxicity, exenatide LAR appeared to improve hepatic injury markers, ALT and AST. ${ }^{51}$

\section{Comparison on efficacy and safety with other drugs}

The DURATION clinical trial program is the largest project involving exenatide LAR; it is sponsored by Lilly and Amylin Pharmaceuticals, the companies that produce exenatide LAR. This program includes a series of studies designed to test the efficacy of exenatide LAR compared to other type 2 diabetes medications (Table 2).

\section{Exenatide LAR vs exenatide twice a day}

The DURATION-1 trial was a 30-week study that compared exenatide LAR $2 \mathrm{mg}$ once weekly to exenatide $10 \mu \mathrm{g}$ BID in 295 patients with type 2 diabetes. ${ }^{48}$ Patients could be naive to drug therapy, or on one or more oral antidiabetic agents. The primary endpoint was the change in $\mathrm{HbA}_{1 \mathrm{c}}$ at 30 weeks. The mean reduction in $\mathrm{HbA}_{1 \mathrm{c}}$ was significantly 
Table 2 DURATION program

\begin{tabular}{|c|c|c|c|}
\hline Study & Duration & Drugs involved & Results \\
\hline DURATION-I ${ }^{48,52}$ & 52 weeks & $\begin{array}{l}\text { Exenatide LAR vs } \\
\text { exenatide BID }\end{array}$ & $\begin{array}{l}\text { Exenatide LAR was more effective in reducing } \mathrm{HbA}_{\mathrm{Ic}} \text {, and FPG than exenatide } \\
\text { BID. Both were associated with a similar decrease of body weight, lipid profile, } \\
\text { and blood pressure. }\end{array}$ \\
\hline DURATION-2 $2^{55,56}$ & 52 weeks & $\begin{array}{l}\text { Exenatide LAR + metformin vs } \\
\text { sitagliptin }+ \text { metformin vs } \\
\text { pioglitazone }+ \text { metformin }\end{array}$ & $\begin{array}{l}\text { Exenatide LAR was more effective in reducing } \mathrm{HbA}_{\mathrm{Ic}} \text {, and body weight compared } \\
\text { to pioglitazone and sitagliptin. Exenatide LAR was more effective than sitagliptin in } \\
\text { reducing FPG. Both pioglitazone and exenatide LAR, but not sitagliptin reduced SBP. }\end{array}$ \\
\hline DURATION-3 $3^{57}$ & 26 weeks & $\begin{array}{l}\text { Exenatide LAR vs } \\
\text { insulin glargine }\end{array}$ & $\begin{array}{l}\text { Exenatide LAR yielded a greater } \mathrm{HbA}_{\mathrm{Ic}} \text {, and PPG decrease compared to insulin } \\
\text { glargine, even if insulin was associated with a greater decrease of FPG. Exenatide } \\
\text { was associated with a greater reduction in body weight. }\end{array}$ \\
\hline DURATION-4 $4^{58}$ & 26 weeks & $\begin{array}{l}\text { Exenatide LAR vs sitagliptin vs } \\
\text { pioglitazone vs metformin }\end{array}$ & $\begin{array}{l}\text { Exenatide LAR and metformin gave a similar decrease of } \mathrm{HbA}_{\mathrm{Ic}} \text {; compared to } \\
\text { pioglitazone, exenatide LAR was slightly less effective in reducing } \mathrm{HbA}_{\mathrm{Ic}} \text {, but } \\
\text { more effective in reducing body weight. }\end{array}$ \\
\hline DURATION-5 53 & 24 weeks & $\begin{array}{l}\text { Exenatide LAR vs } \\
\text { exenatide BID }\end{array}$ & $\begin{array}{l}\text { Exenatide LAR yielded a significant decrease of } \mathrm{HbA} \text {, FPG, body weight } \\
\text { and SBP compared to exenatide BID. }\end{array}$ \\
\hline DURATION-659 & 26 weeks & $\begin{array}{l}\text { Exenatide LAR vs } \\
\text { liraglutide }\end{array}$ & $\begin{array}{l}\text { Exenatide LAR gave a } \mathrm{HbA}_{\mathrm{Ic}} \text { reduction of }-\mathrm{I} .3 \% \text { vs }-\mathrm{I} .5 \text { with liraglutide. } \\
\text { Both drugs showed a similar reduction in body weight. }\end{array}$ \\
\hline
\end{tabular}

Abbreviations: LAR, long acting release; BID, twice a day; FPG, fasting plasma glucose; SBP, systolic blood pressure; PPG, post-prandial glycemia; HbA

greater with exenatide LAR, with reductions from baseline of $1.9 \%$ for exenatide LAR vs $-1.5 \%$ for exenatide BID $(P=0.0023)$. Exenatide once a week resulted in a greater proportion of patients achieving an $\mathrm{HbA}_{1 \mathrm{c}}$ of $7 \%$ or less $(77 \%$ for once a week versus $61 \% \mathrm{BID}, P=0.0039$ ) than treatment with exenatide BID. Body weight decreased progressively in both groups during the 30 -week treatment period (changes from baseline of $-3.7 \mathrm{~kg}$ with exenatide LAR and $-3.6 \mathrm{~kg}$ with exenatide BID; $P=0.89$ ). The change in FPG was significantly greater with exenatide LAR after 30 weeks $(-2.3 \mathrm{mmol} / \mathrm{L}$ for exenatide once a week versus $-1.4 \mathrm{mmol} / \mathrm{L}$ for exenatide BID; $P<0.0001)$.

Consistent with the reductions of FPG, plasma glucagon levels were significantly lower with exenatide once a week. Change from baseline in PPG was significantly greater in patients treated with exenatide BID $(-6.9 \mathrm{mmol} / \mathrm{L})$ than those treated with exenatide LAR $(-5.3 \mathrm{mmol} / \mathrm{L}, P=0.0124)$. Significantly greater reductions from baseline in mean total and low-density lipoprotein-cholesterol levels were observed in patients treated with exenatide LAR when compared to those treated with exenatide BID. Fasting triglyceride concentrations were reduced with both treatments $(-15 \%$ for exenatide LAR and $-11 \%$ for exenatide BID). Patients in both groups had similarly significant improvements in SBP and DBP. The most common adverse events reported with exenatide LAR were nausea (26.4\%) and injection site pruritus (17.6\%). Gastrointestinal complaints including nausea (34.5\%) and vomiting (18.6\%) were the most frequent adverse events reported for patients treated with exenatide BID.

The DURATION-1 study continued for an additional 22 weeks, where patients treated with exenatide LAR continued the same treatment, while patients receiving exenatide BID switched to exenatide LAR. ${ }^{52}$ Patients continuing exenatide LAR maintained $\mathrm{HbA}_{1 \mathrm{c}}$ improvements through 52 weeks $(-2.0 \%)$. Patients switching from exenatide BID to exenatide LAR achieved further $\mathrm{HbA}_{1 \mathrm{c}}$ improvements; both groups exhibited the same $\mathrm{HbA}_{1 \mathrm{c}}$ reduction and mean $\mathrm{HbA}_{1 \mathrm{c}}$ levels $(6.6 \%)$ at week 52 . At week $52,71 \%$ and $54 \%$ of all patients achieved an $\mathrm{HbA}_{1 \mathrm{c}}<7.0 \%$ and $\leq 6.5 \%$, respectively. In both treatment arms, FPG was reduced by $>40 \mathrm{mg} / \mathrm{dL}$ and body weight was reduced by $>4 \mathrm{~kg}$ after 52 weeks. Nausea occurred less frequently in this assessment period and was predominantly mild. No major hypoglycemia was observed.

Similar results were recorded in the DURATION-5 trial, which compared exenatide LAR to exenatide BID in patients with type 2 diabetes. ${ }^{53}$ After 24 weeks of treatment, patients taking exenatide LAR experienced a statistically superior reduction in $\mathrm{HbA}_{1 \mathrm{c}}$ levels of $1.6 \%$ from baseline, compared to a reduction of $0.9 \%$ for exenatide BID. Patients treated with exenatide $\mathrm{LAR}$ achieved a mean $\mathrm{HbA}_{1 \mathrm{c}}$ of $7.1 \%$ compared with a mean $\mathrm{HbA}_{1 \mathrm{c}}$ of $7.7 \%$ in those treated with exenatide BID and reached lower levels of FPG $(-35 \pm 5 \mathrm{mg} / \mathrm{dL}$ versus $-12 \pm 5 \mathrm{mg} / \mathrm{dL} ; P=0.0008)$. Similar reductions in mean body weight from baseline to week 24 were observed in both groups $(-2.3 \pm 0.4 \mathrm{~kg}$ and $-1.4 \pm 0.4 \mathrm{~kg})$. Both treatments were generally well tolerated.

In the DURATION-1 and 5 studies, both exenatide LAR and BID were generally safe and well tolerated, with exenatide LAR being less associated with nausea and vomiting, but more associated with adverse events occurring at the injection site. No major hypoglycemia occurred. Continuous versus intermittent exposure did not impact the 
overall tolerability profile of exenatide, with no evidence of prolonged duration or worsening intensities of adverse events with continuous exposure. ${ }^{54}$

\section{Exenatide $L A R+$ metformin versus sitagliptin + metformin versus pioglitazone + metformin}

In this 26-week randomized, double-blind, double-dummy, superiority trial, patients with uncontrolled type 2 diabetes who had been treated with metformin were randomly assigned to receive $2 \mathrm{mg}$ of injected exenatide LAR once weekly plus oral placebo once daily, $100 \mathrm{mg}$ oral sitagliptin once daily plus injected placebo once weekly, or $45 \mathrm{mg}$ oral pioglitazone once daily plus injected placebo once weekly. ${ }^{55}$ The primary endpoint was change in $\mathrm{HbA}_{1 \mathrm{c}}$ levels between baseline and week 26 .

Treatment with exenatide LAR reduced $\mathrm{HbA}_{1 \mathrm{c}}$ levels by $-1.55 \%$, which was significantly more than treatment with sitagliptin $(-0.9 \%)$ or pioglitazone $(-1.2 \%)$. Treatment differences were $-0.6 \%(P<0.0001)$ for exenatide versus sitagliptin, and $-0.3 \%(P=0.0165)$ for exenatide versus pioglitazone. All treatments improved FPG; exenatide LAR resulted in a significantly greater reduction $(-1.8 \mathrm{mmol} / \mathrm{L})$ than $\mathrm{did}$ sitagliptin $(-0.9 \mathrm{mmol} / \mathrm{L})$, but not pioglitazone $(-1.5 \mathrm{mmol} / \mathrm{L})$. Treatment differences were $-0.9 \mathrm{mmol} / \mathrm{L}(P=0.0038)$ for exenatide LAR versus sitagliptin, and $-0.2 \mathrm{mmol} / \mathrm{L}$ $(P=0.3729)$ for exenatide LAR versus pioglitazone. Fasting insulin was significantly increased at week 26 with exenatide LAR $(3.6 \mu \mathrm{IU} / \mathrm{mL})$ compared with sitagliptin $(0.4 \mu \mathrm{IU} / \mathrm{mL})$ and pioglitazone $(-3.9 \mu \mathrm{IU} / \mathrm{mL})$. Treatment differences were $3.2 \mu \mathrm{IU} / \mathrm{mL}(P=0.0161)$ for exenatide LAR versus sitagliptin, and $7.5 \mu \mathrm{IU} / \mathrm{mL}(P<0.0001)$ for exenatide LAR versus pioglitazone.

Weight loss with exenatide $(-2.3 \mathrm{~kg})$, was significantly greater than with sitagliptin (difference: $-1.5 \mathrm{~kg}, P=0.0002$ ) or pioglitazone (difference: $-5.1 \mathrm{~kg}, P<0.0001$ ). No episodes of major hypoglycemia occurred. The most frequent adverse events with exenatide LAR and sitagliptin were nausea and diarrhea; upper-respiratory-tract infection and peripheral edema were the most frequent events noted with pioglitazone.

After 26 weeks of treatment, the reduction in SBP was significantly greater with exenatide LAR than with sitagliptin in all patients (difference $-4 \mathrm{mmHg}$ ) and in those with abnormal SBP at baseline $(-6 \mathrm{mmHg})$; the difference between exenatide LAR and pioglitazone was not significant in either patient group. Change in DBP at week 26 did not differ significantly between groups. A significant improvement in high-density lipoprotein (HDL) cholesterol was recorded with all treatments, and this improvement was significantly greater with pioglitazone than with exenatide LAR (difference: $0.11 \mathrm{mmol} / \mathrm{L}$ ). Pioglitazone was the only treatment associated with a significant reduction in triglycerides $(-16 \%)$ and an increase in total cholesterol $(0.16 \mathrm{mmol} / \mathrm{L})$, the former of which was significantly different from changes observed with exenatide LAR $(-5 \%)$. All treatments were associated with significant improvements in high-sensitivity C-reactive protein (Hs-CRP) and adiponectin. Exenatide once weekly was the only treatment associated with significantly improved B-type natriuretic peptide and ratio of albumin to creatinine; B-type natriuretic peptide was also significantly greater than with sitagliptin or pioglitazone. Pioglitazone was associated with a significantly greater increase in adiponectin than was exenatide, and was the only treatment associated with significantly improved plasminogen activator inhibitor- 1 and significant worsening of B-type natriuretic peptide.

In the second phase of this trial, ${ }^{56}$ there was an openlabel phase after the first 26 weeks where all randomized oral medications were discontinued and all patients received exenatide LAR once weekly. Evaluable patients who received only exenatide once-weekly, demonstrated significant 52-week improvements in $\mathrm{HbA}_{1 \mathrm{c}}(-1.6 \% \pm 0.1 \%)$, FPG $(-1.8 \pm 0.3 \mathrm{mmol} / \mathrm{L})$, and weight $(-1.8 \pm 0.5 \mathrm{~kg})$. Evaluable patients who switched from sitagliptin to exenatide LAR demonstrated significant incremental improvements in $\mathrm{HbA}_{1 \mathrm{c}}(-0.3 \% \pm 0.1 \%), \mathrm{FPG}(-0.7 \pm 0.2 \mathrm{mmol} / \mathrm{L})$, and weight $(-1.1 \pm 0.3 \mathrm{~kg})$. Patients who switched from pioglitazone to exenatide LAR maintained $\mathrm{HbA}_{1 \mathrm{c}}$ and FPG improvements $(-1.6 \% \pm 0.1 \%,-1.7 \pm 0.3 \mathrm{mmol} / \mathrm{L})$, with significant weight reduction $(-3.0 \pm 0.3 \mathrm{~kg})$. Patients originally treated with sitagliptin also exhibited a significant reduction in weight after switching to exenatide LAR $(-1.1 \mathrm{~kg} ; P=0.0006)$. Patients who received exenatide LAR throughout the trial on average had a $+0.7 \mathrm{~kg}(P=0.0325)$ increase in weight from week 26 to week 52 , resulting in a $-1.8 \pm 0.5 \mathrm{~kg}(P=0.0002)$ reduction from baseline. Patients treated with exenatide LAR for 52 weeks exhibited greater SBP improvements $(-12.2 \mathrm{mmHg})$. Patients who exhibited abnormal SBP at week 26 after treatment with sitagliptin or pioglitazone also demonstrated a greater systolic blood pressure reduction with exenatide LAR ( $-11.3 \mathrm{mmHg}$ and $-9.4 \mathrm{mmHg}$, respectively). Patients who continued exenatide LAR for 52 weeks maintained an improvement in HDL cholesterol levels from baseline; all other lipid variables were not significantly changed from baseline. Patients who switched from sitagliptin to exenatide LAR also maintained the HDL cholesterol improvement observed during the initial 26 weeks of treatment and experienced a 
significant reduction in total cholesterol in this open-label treatment period. Patients who switched from pioglitazone to exenatide LAR significantly reduced their HDL cholesterol $(-0.14 \mathrm{mmol} / \mathrm{L}, P<0.05)$, LDL cholesterol $(-0.14 \mathrm{mmol} / \mathrm{L}$, $P<0.05)$, and total cholesterol $(-0.34 \mathrm{mmol} / \mathrm{L}, P<0.05)$, and increased triglycerides $(+11 \%, P<0.05)$. Treatment with exenatide LAR for 52 weeks was associated with improvements in the urinary albumin/creatinine ratio, B-type natriuretic peptide, and Hs-CRP. Although the mean urinary albumin/creatinine ratio reductions that were observed in both groups that switched to exenatide once weekly were not statistically significant during this treatment period, the urinary albumin/creatinine ratio was significantly reduced from baseline in all three treatment arms.

\section{Exenatide LAR versus insulin glargine}

In this 26-week, open-label, randomized, parallel study, 456 adults with type 2 diabetes who had suboptimum glycemic control despite use of maximum tolerated doses of blood-glucose lowering drugs for 3 months or longer, were randomly assigned to add exenatide LAR ( $2 \mathrm{mg}$, once-a-week injection) or insulin glargine (once-daily injection, starting dose $10 \mathrm{IU}$, target glucose range $4.0-5.5 \mathrm{mmol} / \mathrm{L}$ ) to their blood glucose-lowering regimens. ${ }^{57}$ The primary endpoint was change in $\mathrm{HbA}_{1 \mathrm{c}}$ levels from baseline. Change in $\mathrm{HbA}_{1 \mathrm{c}}$ levels at 26 weeks was greater in patients taking exenatide LAR $(-1.5 \%)$ than in those taking insulin glargine $(-1.3 \%)$, with a treatment difference of $P=0.017$. Exenatide was associated with a progressive decrease in body weight, but insulin glargine was associated with a progressive increase. Mean change in body weight at week 26 compared with baseline was $-2.6 \mathrm{~kg}$ for patients allocated to the exenatide LAR treatment arm, and $1.4 \mathrm{~kg}$ for those taking insulin glargine $(P<0.0001)$. The treatment difference was $-4.0 \mathrm{~kg}, P<0.0001$. Mean FPG was reduced in both groups $(-2.1 \mathrm{mmol} / \mathrm{L}$ with exenatide LAR; $-2.8 \mathrm{mmol} / \mathrm{L}$ with insulin glargine); however, this reduction was greatest among those treated with insulin glargine (treatment difference $0.6 \mathrm{mmol} / \mathrm{L}, P=0.001$ ). Gastrointestinal events including nausea and diarrhea were among the most frequently reported adverse effects for patients taking exenatide LAR; nasopharyngitis and headache were most common adverse events associated with insulin glargine. Gastrointestinal events were all mild or moderate in intensity.

\section{Exenatide LAR versus sitagliptin versus pioglitazone versus metformin}

In the DURATION-4 trial, ${ }^{58}$ patients were randomized to be treated with subcutaneous exenatide LAR $2.0 \mathrm{mg}+$ oral placebo $(\mathrm{n}=248)$, metformin $2,000 \mathrm{mg} /$ day + subcutaneous placebo ( $\mathrm{n}=246)$, pioglitazone $45 \mathrm{mg} /$ day + subcutaneous placebo $(\mathrm{n}=163)$, or sitagliptin $100 \mathrm{mg} /$ day + subcutaneous placebo $(n=163)$ for 26 weeks. Metformin and pioglitazone therapies were increased to maximum-tolerated dosages. Injections with exenatide LAR or placebo were administered weekly, while oral medication or placebo was administered daily. Reductions in $\mathrm{HbA}_{1 \mathrm{c}}$ levels at 26 weeks after treatment were noted with exenatide LAR $(-1.53 \%)$, metformin $(-1.48 \%)$, pioglitazone $(-1.63 \%)$, and sitagliptin $(-1.15 \%)$. Weight changes were $-2.0 \mathrm{~kg}$ with exenatide LAR, $-2.0 \mathrm{~kg}$ with metformin $(P=0.892),+1.5 \mathrm{~kg}$ with pioglitazone $(P<0.001)$, and $-0.8 \mathrm{~kg}$ with sitagliptin $(P<0.001)$. This study showed that exenatide LAR and metformin yielded a similar decrease in $\mathrm{HbA}_{1 \mathrm{c}}$ levels at 26 weeks, as well as a similar benefit of weight reduction and no increased risk of hypoglycemia. On the other hand, treatment with pioglitazone was associated with a slightly greater reduction in $\mathrm{HbA}_{1 \mathrm{c}}$ levels, and with a body weight increase of $+1.5 \mathrm{~kg}$.

\section{Exenatide LAR versus liraglutide}

The yet to be published DURATION-6 trial, is an open-label, 26-week, multicenter clinical study where the authors compared exenatide LAR ( $2 \mathrm{mg}$ weekly) to liraglutide administered at the maximum approved dose of $1.8 \mathrm{mg}$ once daily. ${ }^{59}$ The study was designed to measure $\mathrm{HbA}_{1 \mathrm{c}}$ levels, which is an assessment of average blood sugar, and to evaluate the safety and tolerability profiles of both treatments.

Results showed that patients receiving exenatide LAR once weekly experienced a reduction in $\mathrm{HbA}_{1 \mathrm{c}}$ of $1.3 \%$ from baseline, compared to a reduction of $1.5 \%$ for liraglutide. Gastrointestinal adverse events occurred more frequently among patients taking liraglutide (patients reported experiencing nausea $20 \%$, vomiting $11 \%$, diarrhea $13 \%$ ) compared with patients taking exenatide LAR (nausea 9\%, vomiting $4 \%$, diarrhea $6 \%$ ). Injection site nodules occurred more frequently among exenatide LAR users (10\%) compared with liraglutide users (1\%). There were no major hypoglycemia events in either treatment group.

\section{Cost-effectiveness ratio}

Regarding cost offsets and medication adherence, exenatide LAR and liraglutide had similar average total 6-month follow-up costs (US\$6688 versus US\$7346) among a large, managed care population in the US. However, patients treated with exenatide LAR had significantly lower mean pharmacy costs (US\$2925) than those treated with liraglutide (US\$3272, $P<0.001$ ). There were no significant differences 
in inpatient or outpatient costs or medication adherence between groups. ${ }^{60}$

Similar results were obtained by Gaebler et al. ${ }^{61}$ In the absence of long-term data on the effects of exenatide LAR, the researchers used the Archimedes model to assess the potential effects of exenatide LAR, pioglitazone, and highadherence insulin when compared to moderate-adherence insulin on the incidence of cardiovascular and microvascular outcomes, on life-years, and on costs over 20 years in a cohort of patients with type 2 diabetes mellitus. Over the course of 20 years, exenatide LAR treatment resulted in increased quality-adjusted life-years of $\sim 0.3$ years/person, and a cost savings of $\$ 469$ per life-year when compared to moderate adherence insulin. For pioglitazone or highadherence insulin, quality-adjusted life-years were virtually unchanged, and costs per life-year increased by $\$ 69$ and $\$ 87$ for those in the pioglitazone or high-adherence insulin groups versus those in the moderate-adherence insulin group, respectively. ${ }^{61}$

Data were the same when comparing exenatide LAR, pioglitazone, and sitagliptin. Using the IMS CORE Diabetes Model, a validated computer simulation model, Guillermin et al ${ }^{62}$ estimated that over the course of 35 years, exenatide LAR increased life expectancy by 0.28 years $(13.76 \pm 0.17$ versus $13.48 \pm 0.18)$ while pioglitazone and sitagliptin increased life expectancy by 0.17 years $(13.76 \pm 0.17$ versus $13.59 \pm 0.17)$. Moreover, qualityadjusted life years were increased by 0.28 years in the exenatide LAR group $(9.56 \pm 0.12$ versus $9.28 \pm 0.12)$ and 0.24 years in the pioglitazone or sitagliptin groups $(9.56 \pm 0.12$ versus $9.32 \pm 0.12)$. Exenatide LAR was associated with lower lifetime complication costs; compared with sitagliptin or pioglitazone, exenatide LAR saved US\$2215 (US\$55,647 $\pm \$ 2039$ versus US\$57,862 \pm \$2159) compared to sitagliptin and US\$933 (US\$55,647 $\pm \$ 2039$ versus US\$56,580 \pm 2007 ) compared to pioglitazone in direct costs per patient. Cost-savings resulted mainly from a lower projected cumulative incidence of cardiovascular diseases and neuropathic complications. ${ }^{62}$

\section{Discussion}

From the studies reported above, it is evident that exenatide LAR can be a valid option for the treatment of type 2 diabetes mellitus because it seems to be as effective as other antidiabetic drugs (with the exception of liraglutide and pioglitazone) in reaching adequate glycemic control. When compared to pioglitazone, ${ }^{55,56,58}$ exenatide LAR was slightly less effective in reducing $\mathrm{HbA}_{1 \mathrm{c}}$, but was more effective in reducing body weight. Exenatide LAR improved cardiovascular risk markers such as B-type natriuretic peptide, and HsCRP. ${ }^{56}$ When compared to insulin, ${ }^{57}$ exenatide LAR appeared to be as effective as insulin in reducing $\mathrm{HbA}_{1 \mathrm{c}}$ and was more effective in reducing body weight. Finally, exenatide LAR was superior to sitagliptin in improving glycemic control, body weight, and $\beta$-cell function. ${ }^{55,58}$ When comparing the two exenatide formulations, exenatide LAR was more effective in reducing $\mathrm{HbA}_{1 \mathrm{c}}$ levels and in protecting $\beta$-cell function compared to exenatide BID; exenatide LAR was also associated with fewer gastrointestinal adverse events, including nausea and vomiting compared to exenatide BID. ${ }^{48,52-54}$

On the other hand, when directly compared to liraglutide, exenatide LAR was inferior in reducing $\mathrm{HbA}_{1 \mathrm{c}}(-1.3 \%$ from baseline versus $-1.5 \%$ ); however, gastrointestinal adverse events occurred more frequently among liraglutide patients ( $20 \%$ of patients reported experiencing nausea, $11 \%$ reported vomiting, and $13 \%$ reported suffering from diarrhea) compared with exenatide LAR patients (nausea $9 \%$, vomiting $4 \%$, diarrhea $6 \%$ ), even if the injection site nodule occurred more frequently amongst exenatide LAR users (10\%) compared with liraglutide users (1\%).

Other than being effective and safe, exenatide LAR also exhibited a favorable cost-effectiveness ratio. Using validated computer simulation models, exenatide LAR seemed to improve patients' overall health and decrease diabetes-related complication costs compared with liraglutide, ${ }^{60}$ insulin, ${ }^{61}$ sitagliptin, or pioglitazone, ${ }^{62}$ and it also improved the patients' lipid profiles and SBP levels. However, the DURATION program lasted up to 1 year and did not look for cardiovascular end-points; long-term studies are therefore needed to evaluate the long-term effects of exenatide LAR not only in achieving glycemic control, but to assess for cardiovascular risk. In this regard, the ongoing EXenatide Study of Cardiovascular Event Lowering study (ClinicalTrials.gov Identifier: NCT01144338) ${ }^{63}$ will compare the impact of including exenatide LAR as part of usual care and compare the results with usual care without exenatide across major cardiovascular outcomes, with cardiovascular-related death, nonfatal myocardial infarction, or nonfatal stroke as the primary endpoints. The study started in June 2010 and is estimated to be completed in March 2017. Another limitation is that, as we have already stated above, the DURATION program was sponsored by Lilly and Amylin Pharmaceuticals, the companies producing exenatide LAR; this should be considered in the interpretation of data presented. 


\section{Conclusion}

We can conclude that exenatide LAR can be a valid option for the treatment of type 2 diabetes mellitus because of its efficacy in reducing $\mathrm{HbA}_{1 \mathrm{c}}$ and because of its pleiotropic effects, such as the reduction of blood pressure, the improvement of lipid profile, and the positive effect on body weight. Moreover, exenatide LAR has a favorable cost/effectiveness ratio, and its once weekly administration may help to increase patient compliance.

\section{Disclosure}

The authors have no relevant affiliations or financial involvement with any organization or entity with a financial interest in or financial conflict with the subject matter or materials discussed in the manuscript. This includes employment, consultancies, honoraria, stock ownership or options, expert testimony, grants or patents received or pending, or royalties. No writing assistance was utilized in the production of this manuscript.

\section{References}

1. Weir GC, Leahy JL. Pathogenesis of non-insulin-dependent (type II) diabetes mellitus. In: Kahn CR, Weir GE, editors. Joslin's Diabetes Mellitus. 13th ed. Philadelphia, PA: Lea and Febiger; 1994 : 240-264.

2. Bogardus C. Metabolic abnormalities in the development of non-insulindependent diabetes mellitus. In: LeRoith D, Taylor SI, Olefski JM, editors. Diabetes mellitus. Philadelphia, PA: Lippincot-Raven Publishers; 1996:459.

3. DeFronzo RA. Lilly Lecture 1987. The triumvirate: beta-cell, muscle, liver. A collision responsible for NIDDM. Diabetes. 1988;37(6): 667-687.

4. Weyer C, Bogardus C, Mott DM, Pratley RE. The natural history of insulin secretory dysfunction and insulin resistance in the pathogenesis of type 2 diabetes mellitus. J Clin Invest. 1999;104(6):787-794.

5. Holman RR, Paul SK, Bethel MA, Matthews DR, Neil HA. 10-year follow-up of intensive glucose control in type 2 diabetes. $N$ Engl J Med. 2008;359(15):1577-1589.

6. de Boer IH, Rue TC, Cleary PA, et al; Diabetes Control and Complications Trial/Epidemiology of Diabetes Interventions and Complications Study Research Group. Long-term renal outcomes of patients with type 1 diabetes mellitus and microalbuminuria: an analysis of the Diabetes Control and Complications Trial/Epidemiology of Diabetes Interventions and Complications cohort. Arch Intern Med. 2011;171(5):412-420.

7. American Diabetes Association. Standards of medical care in diabetes 2012. Diabetes Care. 2012;35 Suppl 1:S11-S63.

8. Bailey CJ, Turner RC. Metformin. N Engl J Med. 1996;334: 574-583.

9. DeFronzo RA, Goodman AM. Efficacy of metformin in patients with non-insulin-dependent diabetes mellitus. The Multicenter Metformin Study Group. N Engl J Med. 1995;333(9):541-549.

10. Groop L. Sulfonylureas in NIDDM. Diabetes Care. 1992;15: 737-747.

11. Malaisse WJ. Pharmacology of the meglitinide analogs: new treatment options for type 2 diabetes mellitus. Treat Endocrinol. 2003;2(6): 401-414

12. Derosa G, Maffioli P. Efficacy and safety profile evaluation of acarbose alone and in association with other antidiabetic drugs: a systematic review. Clin Ther. 2012;34(6):1221-1236.
13. Krentz AJ, Bailey CJ. Oral antidiabetic agents: current role in type 2 diabetes mellitus. Drugs. 2005;65(3):385-411.

14. Yki-Jarvinen H. Thiazolidinediones. N Engl J Med. 2004;351(11): 1106-1118.

15. Derosa G, Maffioli P. Effects of thiazolidinediones and sulfonylureas in patients with diabetes. Diabetes Technol Ther. 2010;12(6): 491-501.

16. Singh S, Loke YK, Furberg CD. Thiazolidinediones and heart failure: a teleo-analysis. Diabetes Care. 2007;30(8):2148-2153.

17. Derosa G, Tinelli C, Maffioli P. Effects of pioglitazone and rosiglitazone combined with metformin on body weight in people with diabetes. Diabetes Obes Metab. 2009;11(12):1091-1099.

18. Meymeh RH, Wooltorton E. Diabetes drug pioglitazone (Actos): risk of fracture. CMAJ. 2007;177(7):723-724.

19. Holst JJ. The physiology of glucagon-like peptide 1. Physiol Rev. 2007;87(4):1409-1439.

20. Tourrel C, Zhao Bailbé D, Meile MJ, Kergoat M, Portha B. Glucagon-like peptide-1 and exendin-4 stimulate beta-cell neogenesis in streptozotocin-treated newborn rats resulting in persistently improved glucose homeostasis at adult age. Diabetes. 2001;50(7): 1562-1570

21. Hui H, Nourparvar A, Zhao X, Perfetti R. Glucagon-like peptide-1 inhibits apoptosis of insulin-secreting cells via a cyclic 5 -adenosine monophosphate-dependent protein kinase A- and a phosphatidylinositol 3-kinase-dependent pathway. Endocrinology. 2003;144(4):1444-1455.

22. Perfetti R, Zhou J, Doyle ME, Egan JM. Glucagon-like peptide-1 induces cell proliferation and pancreatic-duodenum homeobox-1 expression and increases endocrine cell mass in the pancreas of old, glucose-intolerant rats. Endocrinology. 2000;141(12):4600-4605.

23. Derosa G, Carbone A, Franzetti I, et al. Effects of a combination of sitagliptin plus metformin vs metformin monotherapy on glycemic control, $\beta$-cell function and insulin resistance in type 2 diabetic patients. Diabetes Res Clin Pract. June 8, 2012. [Epub ahead of print.]

24. Derosa G, Maffioli P, Salvadeo SA, et al. Effects of sitagliptin or metformin added to pioglitazone monotherapy in poorly controlled type 2 diabetes mellitus patients. Metabolism. 2010;59(6): 887-895.

25. Derosa G, Ragonesi PD, Carbone A, et al. Vildagliptin added to metformin on $\beta$-cell function after a euglycemic hyperinsulinemic and hyperglycemic clamp in type 2 diabetes patients. Diabetes Technol Ther. 2012;14(6):475-484.

26. Derosa G, Maffioli P, Ferrari I, et al. Effects of one year treatment of vildagliptin added to pioglitazone or glimepiride in poorly controlled type 2 diabetic patients. Horm Metab Res. 2010;42(9): 663-669.

27. Derosa G, Maffioli P. Patient considerations and clinical utility of a fixed dose combination of saxagliptin/metformin in the treatment of type 2 diabetes. Diabetes Metab Syndr Obes. 2011;4:263-271.

28. Derosa G, Maffioli P. Dipeptidyl peptidase-4 inhibitors: 3 years of experience. Diabetes Technol Ther. 2012;14(4):350-364.

29. Derosa G, Maffioli P. GLP-1 agonists exenatide and liraglutide: a review about their safety and efficacy. Curr Clin Pharmacol. 2012;7(3):214-228.

30. Derosa G, Franzetti IG, Querci F, et al. Exenatide plus metformin compared with metformin alone on $\beta$-cell function in patients with Type 2 diabetes. Diabet Med. April 30, 2012. doi: 10.1111/j.1464-5491. 2012.03699.x. [Epub ahead of print.]

31. Derosa G, Putignano P, Bossi AC, et al. Exenatide or glimepiride added to metformin on metabolic control and on insulin resistance in type 2 diabetic patients. Eur J Pharmacol. 2011;666(1-3): $251-256$.

32. Derosa G, Maffioli P, Salvadeo SA, et al. Exenatide versus glibenclamide in patients with diabetes. Diabetes Technol Ther. 2010; 12(3):233-240.

33. Dickersin K, Scherer R, Lefebvre C. Identifying relevant studies for systematic reviews. BMJ. 1994;309(6964):1286-1291. 
34. Jadad AR, Moore RA, Carroll D, et al. Assessing the quality of randomized clinical trials: is blinding necessary? Control Clin Trials. 1996;17(1):1-12.

35. Eng J, Kleinman WA, Singh L, Singh G, Raufman JP. Isolation and characterization of exendin-4, an exendin-3 analogue, from Heloderma suspectum venom. Further evidence for an exendin receptor on dispersed acini from guinea pig pancreas. J Biol Chem. 1992;267(11): 7402-7405.

36. Young AA. Chapter 14. Glucagon-like peptide-1, exendin and insulin sensitivity. In: Hansen B, Shafrir E, editors. Insulin Resistance and Insulin Resistance Syndrome. New York: Taylor and Francis; 2002: 235-262.

37. Knudsen LB, Nielsen PF, Huusfeldt PO, et al. Potent derivatives of glucagon-like peptide-1 with pharmacokinetic properties suitable for once daily administration. J Med Chem. 2000;43(9):1664-1669.

38. Knudsen LB. Glucagon-like peptide-1: the basis of a new class of treatment for type 2 diabetes. J Med Chem. 2004;47(17): 4128-4134.

39. Parkes D, Jodka C, Smith P, et al. Pharmacokinetic actions of exenatide-4 in the rat: comparison with glucagon-like peptide-1. Drug Dev Res. 2001;53:260-267.

40. Copley K, McCowen K, Hiles R, Nielsen LL, Young A, Parkes DG. Investigation of exenatide elimination and its in vivo and in vitro degradation. Curr Drug Metab. 2006;7(4):367-374.

41. Simonsen L, Holst JJ, Deacon CF. Exendin-4, but not glucagon-like peptide-1, is cleared exclusively by glomerular filtration in anaesthetised pigs. Diabetologia. 2006;49(4):706-712.

42. Linnebjerg H, Kothare PA, Park S, et al. Effect of renal impairment on the pharmacokinetics of exenatide. Br J Clin Pharmacol. 2007;64(3): 317-327.

43. Kim D, MacConell L, Zhuang D, et al. Effects of once-weekly dosing of a long-acting release formulation of exenatide on glucose control and body weight in subjects with type 2 diabetes. Diabetes Care. 2007;30(6):1487-1493.

44. Malone J, Trautmann M, Wilhelm K, Taylor K, Kendall DM. Exenatide once weekly for the treatment of type 2 diabetes. Expert Opin Investig Drugs. 2009;18(3):359-367.

45. Tracy MA, Ward KL, Firouzabadian L, et al. Factors affecting the degradation rate of poly(lactide-co-glycolide) microspheres in vivo and in vitro. Biomaterials. 1999;20(11):1057-1062.

46. European Medicines Agency. Bydureon. EPAR summary for the public [document on the Internet]. London, UK: European Medicines Agency [updated May 2011]. Available from: http://www.ema.europa.eu/ docs/en_GB/document_library/EPAR_-_Summary_for_the_public/ human/002020/WC500108240.pdf. Accessed May 13, 2011.

47. Department of Health and Human Services. Summary Review [document on the Internet]. Silver Spring, MD: Center for Drug Evaluation and Research [updated January 27, 2012]. Available from: http://www. accessdata.fda.gov/drugsatfda_docs/nda/2012/022200Orig1s000SumR. pdf. Accessed Aug 5, 2012.

48. Drucker DJ, Buse JB, Taylor K, et al; for DURATION-1 Study Group. Exenatide once weekly versus twice daily for the treatment of type 2 diabetes: a randomised, open-label, non-inferiority study. Lancet. 2008; 372(9645):1240-1250.

49. Novo Nordisk Inc. NDA 22-341 VICTOZA ${ }^{\circledR}$ (Liraglutide [rDNA origin] Injection). Risk Evaluation and Mitigation Strategy (REMS) [document on the Internet]. Silver Spring, MD: Food and Drug Association [updated May 2011]. Available from: http://www.fda.gov/downloads/Drugs/ DrugSafety/PostmarketDrugSafetyInformationforPatientsandProviders/ UCM202063.pdf. Accessed May 13, 2011.

50. Pharmalot. Lily's once-weekly byetta may have cancer risk [homepage on the Internet]. Hamilton, NJ: UBM Canon. Available from: http:// www.pharmalot.com/2010/04/lillys-once-weekly-byetta-may-havecancer-risk/. Accessed April 12, 2010.
51. Nielsen LL, Okerson T, Holcombe J, Hoogwerf B. Effects of exenatide on diabetes, obesity, cardiovascular risk factors, and hepatic biomarkers in patients with type 2 diabetes. J Diabetes Sci Technol. 2008;2(2): 255-260.

52. Buse JB, Drucker DJ, Taylor KL, et al; for DURATION-1 Study Group. DURATION-1: exenatide once weekly produces sustained glycemic control and weight loss over 52 weeks. Diabetes Care. 2010;33(6): $1255-1261$.

53. Blevins T, Pullman J, Malloy J, et al. DURATION-5: exenatide once weekly resulted in greater improvements in glycemic control compared with exenatide twice daily in patients with type 2 diabetes. $J$ Clin Endocrinol Metab. 2011;96(5):1301-1310.

54. Ridge T, Moretto T, Macconell L, et al. Comparison of safety and tolerability with continuous (exenatide once weekly) or intermittent (exenatide twice daily) GLP-1 receptor agonism in patients with type 2 diabetes. Diabetes Obes Metab. June 26, 2012. doi: 10.1111/j.14631326. 2012.01639.x. [Epub ahead of print.]

55. Bergenstal RM, Wysham C, MacConell L, et al; for DURATION-2 Study Group. Efficacy and safety of exenatide once weekly versus sitagliptin or pioglitazone as an adjunct to metformin for treatment of type 2 diabetes (DURATION-2): a randomised trial. Lancet. 2010;376(9739):431-439.

56. Wysham C, Bergenstal R, Malloy J, et al. DURATION-2: efficacy and safety of switching from maximum daily sitagliptin or pioglitazone to once-weekly exenatide. Diabet Med. 2011;28(6):705-714.

57. Diamant M, Van Gaal L, Stranks S, et al. Once weekly exenatide compared with insulin glargine titrated to target in patients with type 2 diabetes (DURATION-3): an open-label randomised trial. Lancet. 2010;375(9733):2234-2243.

58. Russell-Jones D, Cuddihy RM, Hanefeld M, et al; for DURATION-4 Study Group. Efficacy and safety of exenatide once weekly versus metformin, pioglitazone, and sitagliptin used as monotherapy in drug-naïve patients with type 2 diabetes (DURATION-4): a 26-week double-blind study. Diabetes Care. 2012;35(2):252-258.

59. Lilly. DURATION-6 Top-Line Study Results Announced [homepage on the Internet]. Indianapolis, IN: Eli Lilly and Company. Available from: http://investor.lilly.com/releasedetail2.cfm?ReleaseID $=554248$. Accessed March 25, 2011.

60. Pelletier EM, Pawaskar M, Smith PJ, Best JH, Chapman RH. Economic outcomes of exenatide vs liraglutide in type 2 diabetes patients in the United States: results from a retrospective claims database analysis. J Med Econ. April 26, 2012. [Epub ahead of print.]

61. Gaebler JA, Soto-Campos G, Alperin P, et al. Health and economic outcomes for exenatide once weekly, insulin, and pioglitazone therapies in the treatment of type 2 diabetes: a simulation analysis. Vasc Health Risk Manag. 2012;8:255-264.

62. Guillermin AL, LloydA, Best JH, Deyoung MB, SamyshkinY, Gaebler JA. Long-term cost-consequence analysis of exenatide once weekly vs sitagliptin or pioglitazone for the treatment of type 2 diabetes patients in the United States. J Med Econ. 2012;15(4):654-663.

63. Amylin Pharmaceuticals, LLC. Exenatide Study of Cardiovascular Event Lowering Trial (EXSCEL). A Randomized, Placebo Controlled Clinical Trial to Evaluate Cardiovascular Outcomes After Treatment With Exenatide Once Weekly in Patients With Type 2 Diabetes Mellitus In: ClinicalTrials.gov [website on the Internet]. Bethesda, MD: US National Library of Medicine; 2011 [updated August 26, 2011]. Available from: http://clinicaltrials.gov/ct2/show/NCT01144338. NLM identifier: NCT01144338. Accessed September 3, 2012. 
Research and Reports in Endocrine Disorders

Dovepress

\section{Publish your work in this journal}

Research and Reports in Endocrine Disorders is an international, peerreviewed, open access journal publishing original research, reports, reviews and commentaries on all areas of endocrinology, endocrine disorders and therapeutic interventions. The manuscript management system is completely online and includes a very quick and fair

Submit your manuscript here: http://www.dovepress.com/research-and-reports-in-endocrine-disorders-journal

peer-review system. Visit http://www.dovepress.com/testimonials.php to read real quotes from published authors. 